\title{
Alginate Nanohydrogels as a Biocompatible Platform for the Controlled Release of a Hydrophilic Herbicide
}

\author{
Fiora Artusio $^{1} \mathbb{D}$, Dario Casà ${ }^{1}$, Monica Granetto ${ }^{2}$, Tiziana Tosco ${ }^{2} \mathbb{D}$ and Roberto Pisano ${ }^{1, * \mathbb{D}}$ \\ 1 Department of Applied Science and Technology (DISAT), Politecnico di Torino, 24 Corso Duca Degli Abruzzi, \\ 10129 Torino, Italy; fiora.artusio@polito.it (F.A.); dario.casa@studenti.polito.it (D.C.) \\ 2 Department of Environment, Land and Infrastructure Engineering (DIATI), Politecnico di Torino, 24 Corso \\ Duca Degli Abruzzi, 10129 Torino, Italy; monica.granetto@polito.it (M.G.); tiziana.tosco@polito.it (T.T.) \\ * Correspondence: roberto.pisano@polito.it
}

Citation: Artusio, F.; Casà, D.; Granetto, M.; Tosco, T.; Pisano, R. Alginate Nanohydrogels as a Biocompatible Platform for the Controlled Release of a Hydrophilic Herbicide. Processes 2021, 9, 1641. https://doi.org/10.3390/pr9091641

Academic Editors: Arkadiusz Gola, Izabela Nielsen and Patrik Grznár

Received: 31 July 2021

Accepted: 9 September 2021

Published: 11 September 2021

Publisher's Note: MDPI stays neutral with regard to jurisdictional claims in published maps and institutional affiliations.

Copyright: (c) 2021 by the authors. Licensee MDPI, Basel, Switzerland. This article is an open access article distributed under the terms and conditions of the Creative Commons Attribution (CC BY) license (https:// creativecommons.org/licenses/by/ $4.0 /)$.

\begin{abstract}
The large-scale application of volatile and highly water-soluble pesticides to guarantee crop production can often have negative impacts on the environment. The main loss pathways are vapor drift, direct volatilization, or leaching of the active substances. Consequently, the pesticide can either accumulate and/or undergo physicochemical transformations in the soil. In this scenario, we synthesized alginate nanoparticles using an inverse miniemulsion template in sunflower oil and successfully used them to encapsulate a hydrophilic herbicide, i.e., dicamba. The formulation and process conditions were adjusted to obtain a unimodal size distribution of nanohydrogels of about $20 \mathrm{~nm}$. The loading of the nanoparticles with dicamba did not affect the nanohydrogel size nor the particle stability. The release of dicamba from the nanohydrogels was also tested: the alginate nanoparticles promoted the sustained and prolonged release of dicamba over ten days, demonstrating the potential of our preparation method to be employed for field application. The encapsulation of hydrophilic compounds inside our alginate nanoparticles could enable a more efficient use of pesticides, minimizing losses and thus environmental spreading. The use of biocompatible materials (alginate, sunflower oil) also guarantees the absence of toxic additives in the formulation.
\end{abstract}

Keywords: miniemulsion; cross-linking; nanoparticle; alginate; nanopesticide; release; hydrogel

\section{Introduction}

Pesticides are massively used worldwide in agriculture to control pests, including insects, weeds, rodents, fungi, and any armful organism in crop production and livestock management [1]. Their use is fundamental in enhancing crop yield production in a scenario of increasing global population, which is expected to reach 9.8 billion by 2050 [2,3]. Several studies show how crop management, without the use of pesticides, would averagely result in 35\% loss of potential yields in the pre-harvest phase [4], and another 35\% during transformation, transport, and other processing steps [5]. On the other hand, 10 to $75 \%$ of applied pesticides does not actually reach the target organisms and is dispersed in the environment [6,7]. As a consequence, significantly higher doses, compared to those really needed to control target pests, must be currently applied for most agrochemicals, with potential detrimental effects for environmental compartments. Depending on their specific characteristics, pesticides spread into the environmental matrices, where they can either undergo physical/chemical transformations (e.g., degradation, hydrolysis, oxidation, etc.) [8] or accumulate [9]. Unintended losses and consequent environmental spreading are particularly relevant for highly soluble and volatile pesticides, having a high potential of diffusion and dispersion in surface and subsurface water and in the atmosphere. Among these, dicamba is a prime example. Dicamba is a post-emergence selective herbicide that is active against broadleaf weeds and currently applied in different crops such as maize, wheat, and sorghum. It belongs to the family of benzoic acids and is characterized by a low dissociation constant $(\mathrm{pKa}=1.89)$, high solubility in water $(6.5 \mathrm{~g} / \mathrm{L}$ at $\mathrm{pH} \approx 2$, 
and significantly higher at higher $\mathrm{pH}$ ), and moderate volatility in air (vapor pressure $=$ $3.4 \times 10^{-5} \mathrm{mmHg}$ ) [10]. The presence of dicamba in its dissociated form at $\mathrm{pH}$ values typically detected in environmental conditions leads to a generalized low soil adsorption capacity [11-13] and consequent high leaching potential [14-16]. In the presence of a rainfall or sprinkling irrigation right after application, a major part of dicamba in traditional formulations can be mobilized from top soil and leaves and lost due to infiltration in soil. Moderate volatility can cause both dicamba vapor drift-i.e., loss during or right after the application for wind blows or evaporation of droplet from pressurized nozzles [17,18]—and direct volatilization after it has been applied to the target area $[19,20]$, with a consequent potential damage to neighbor crops and safety risks for the operators and, more in general, for the nearby population [21].

In the last decade, nanotechnologies started playing a key role in agriculture; advanced solutions have been developed mainly in terms of new sensors for real-time monitoring of relevant parameters (nanobiosensors) [22], and smart delivery systems to protect crops against pests (nanopesticides) or to supply nutrients and fertilizers (nanofertilizers) [2,22-24]. Nanopesticides have been typically proposed to overcome the technical limitations of their conventional analogues. On the one hand, the applicability of poorly water-soluble active ingredients (AIs, i.e., the molecules exploiting the pesticidal effect) to pest targeting is limited by their scarce solubility. On the other hand, hydrophilic AIs may need engineered solutions to control their release over time, thus guaranteeing a specific concentration for a prolonged time, and to limit their leaching in the subsoil (following, for example, irrigation or precipitations). To this aim, the AI can be embedded, adsorbed, or encapsulated in a nanoparticle or a micelle that modifies its solubility, mobility, lifetime, and/or bioavailability. Nanocarriers, such as polymeric nanohydrogels, nanospheres, nanocapsules, porous hollow silica nanoparticles, double-layered hydroxides, and modified or natural clays have been proposed $[2,25,26]$. For example, the use of an alginate-based nanohydrogel can positively influence dicamba leaching potential, reducing the amount of AI that could be washed out or volatilized after treatment $[20,27]$. Reduced leaching of alginate-based controlled-release formulations has also been reported for several other compounds, e.g., carbofuran [28], metribuzin [29], nitrogen, phosphorous, and potassium [30].

The AI polarity plays a key role in the selection of the most appropriate nanocarrier configuration. The AI must display a high affinity toward the chemistry of the nanocarrier to get high AI loadings and limited leakage during storage. In this scenario, emulsified systems offer a versatile platform for the encapsulation of hydrophilic or hydrophobic compounds, depending on the composition of the continuous and the dispersed phases.

Miniemulsions, also known as nanoemulsions, are thermodynamically unstable systems that must be stabilized against coalescence by adding surfactants [31]. The miniemulsion formation requires an energy input, coming from hot/cold homogenization [32], high-pressure homogenization [33], ultrasounds [34], or even phase transitions [35,36]. Direct (oil-in-water, O/W) miniemulsions are characterized by oily droplets, where hydrophobic AIs can readily be solubilized [25,37]. Conversely, inverse (water-in-oil, W/O) miniemulsions can be employed for the encapsulation of hydrophilic AIs as an aqueous dispersed phase is homogenized into an oily continuous phase [37-39].

When monomers are added to the formulation, $\mathrm{O} / \mathrm{W}$ and $\mathrm{W} / \mathrm{O}$ miniemulsions can act as templates for the synthesis of polymeric nanoparticles, which can be obtained with several processing methods. Among these, sol-gel techniques, physical cross-linking, and UV or thermal polymerization are often employed [25,40,41]. Miniemulsion polymerization enables the preservation of droplet size thanks to the confinement of the cross-linking within the dispersed phase [42]. Therefore, each droplet acts as a "nanoreactor", where polymerization occurs as in a closed system. The final particle size corresponds to the templating droplet size and can be adjusted by acting on the homogenization conditions. Miniemulsion polymerization has been extensively used for preparing nanoparticles for drug delivery purposes [43], magnetic particles, clay/polymer nanocomposites [44], or hybrid nanomaterials $[45,46]$. 
In this work, the inverse miniemulsion approach was exploited to produce polymeric nanocarriers for the encapsulation of dicamba. Sodium alginate and sunflower oil were selected as the nanocarrier material and the continuous oily phase, respectively, due to their high biocompatibility and biodegradability, thus ensuring that no potentially harmful substance is introduced in the environment along with the AI. Sodium alginate is a food-grade linear polysaccharide that is soluble in water and can readily undergo physical cross-linking: bivalent cations substitute sodium ions, resulting in an egg box-like cross-linked network. Alginate has been successfully used for nanocarrier synthesis via complexation and internal or external gelation after emulsification in oily phases [25,47,48], but to the authors' knowledge, this is the first time it is used in inverse miniemulsions for agricultural uses. In addition, its application to the pharmaceutical and biological field is very limited compared to other polysaccharides such as agarose [49-51].

In this study, the synthesis, characterization, encapsulation capacity, and modulated release of dicamba from alginate nanohydrogels obtained via inverse miniemulsion are reported and discussed, opening perspectives for the application of this approach to the encapsulation of highly soluble, mobile, and/or volatile pesticides. Particles with an average size of $20 \mathrm{~nm}$ and good colloidal stability were obtained and successfully loaded with dicamba. The sustained release of AI from the alginate nanohydrogels was guaranteed over ten days.

\section{Materials and Methods}

\subsection{Materials}

All the chemicals were reagent-grade and used as received. 3,6-Dichloro-2-methoxybenzoic acid (dicamba, $\geq 98 \%$ ) was supplied by Alfa Chemistry (Ronkonkoma, NY, USA). Sodium alginate (from brown algae, $\mathrm{M} / \mathrm{G}=1.49, M_{w}=396 \mathrm{kDa}$ [52]), calcium chloride, and sodium hydroxide were purchased from Merck (Milano, Italy). Pluronic PE 6100 (HLB = 3) was obtained from BASF (Ludwigshafen, Germany), whereas sunflower oil was acquired in a grocery store (Simply, Torino, Italy). Water was deionized and filtered (ELGA Vision 250 disposable deionizer, Veolia Water Technologies, Saint-Maurice, France).

\subsection{Synthesis of Unloaded and Loaded Carriers}

Deionized water and non-ionic surfactant were selected because of the absence of ions, which could interfere with the alginate gelification. Nanohydrogels were synthesized starting from an inverse miniemulsion template: $0.25-0.4 \mathrm{~g}$ of Pluronic PE 6100 were dissolved in $75 \mathrm{~mL}$ of sunflower oil to prepare the continuous phase. A 1-2 wt \% aqueous solution of sodium alginate was separately prepared by vigorous stirring for $1 \mathrm{~h}$. To prepare the miniemulsion, $1 \%(v / v)$ alginate solution was added to the oily phase and mixed by Ultra Turrax (T25, IKA, Staufen, Germany) at 8000-14,000 rpm for $10 \mathrm{~min}$. Then, $0.75 \mathrm{~mL}$ of $0.2 \mathrm{M} \mathrm{CaCl}_{2}$ solution were added to trigger the cross-linking of alginate droplets and obtain the nanohydrogels. The operation was performed under mixing, and the system was homogenized for another $5 \mathrm{~min}$. All the formulations and operating conditions employed in this study are reported in Table 1. 
Table 1. List of formulations and operating conditions for the preparation of miniemulsions (M), unloaded nanohydrogels $(\mathrm{H})$, and nanohydrogels loaded with dicamba (HD).

\begin{tabular}{ccccc}
\hline Sample Code & Pluronic, $\mathbf{g}$ & UT Speed, rpm & Alginate, wt $\mathbf{o}$ & $\begin{array}{c}\text { Dicamba, } \\
\mathbf{m g} / \mathbf{m L}\end{array}$ \\
\hline M1 & 0.25 & 14,000 & - & - \\
M2 & 0.30 & 14,000 & - & - \\
M3 & 0.35 & 14,000 & - & - \\
M4 & 0.40 & 14,000 & - & - \\
M5 & 0.30 & 8000 & - & - \\
M6 & 0.30 & 10,000 & - & - \\
H1 & 0.30 & 8000 & 1 & - \\
H2 & 0.30 & 10,000 & 1 & - \\
H3 & 0.30 & 14,000 & 1 & - \\
H4 & 0.30 & 10,000 & 2 & 3 \\
HD1 & 0.30 & 10,000 & 1 & $30(+\mathrm{NaOH})$ \\
HD2 & 0.30 & 10,000 & 1 & $125(+\mathrm{NaOH})$ \\
HD3 & 0.30 & 10,000 & 1 & 1 \\
HD4 & 0.30 & 10,000 & 1 & - \\
\hline
\end{tabular}

For dicamba-loaded nanohydrogels, a direct incorporation was employed. Dicamba was dissolved in the $0.2 \mathrm{M} \mathrm{CaCl}_{2}$ solution. For small dicamba concentrations, i.e., $\leq 3 \mathrm{mg} / \mathrm{mL}$, the pesticide was directly dissolved in deionized water for $30 \mathrm{~min}$ with the help of an ultrasonic bath (Bandelin, Sonorex, Germany). After complete dissolution, $\mathrm{CaCl}_{2}$ was added. Larger concentrations required a different procedure as the solubility of dicamba strongly depends on $\mathrm{pH}$. Dicamba was first dissolved in deionized water to obtain a $\mathrm{pH} 3$ solution. Then, $5 \mathrm{M} \mathrm{NaOH}$ was added to raise the $\mathrm{pH}$ to 4 . A new dicamba addition was performed to lower the $\mathrm{pH}$ to 3 , and so on. When the target dicamba concentration was reached, the solution was exposed to ultrasounds for $30 \mathrm{~min}$. In this way, dicamba concentrations in water as high as $250 \mathrm{mg} / \mathrm{mL}$ could be obtained. In parallel, $10 \mathrm{~mL}$ of $0.4 \mathrm{M} \mathrm{CaCl}_{2}$ solution was prepared and mixed with an equal volume of dicamba solution. All the other synthesis conditions were unmodified. The experimental set-up is summarized in Figure 1.

(a)

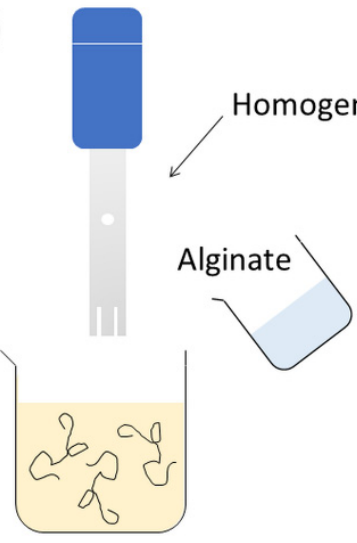

Surfactant (b)

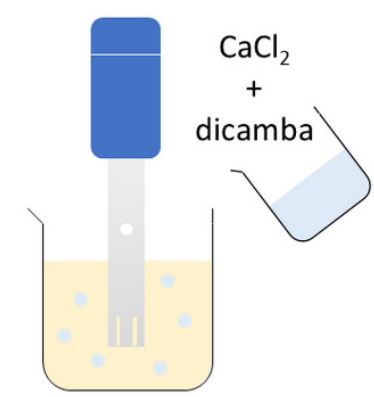

Oil (c)

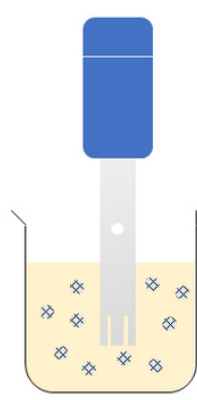

Nanohydrogel

Figure 1. Experimental set-up for the synthesis of dicamba-loaded alginate nanohydrogels: (a) addition of the alginate solution to the oily phase and mixing with Ultra Turrax homogenizer, (b) addition of $\mathrm{CaCl}_{2}$ and dicamba solution to the miniemulsion, and (c) nanohydrogels obtained thanks to the cross-linking of alginate droplets.

Unloaded and dicamba-loaded nanohydrogels were studied in the form of oily suspension (i.e., alginate nanoparticles dispersed in the sunflower oil used for the synthesis), if not stated otherwise. For dimensional analyses only, aqueous suspensions of the nanohy- 
drogels were also prepared. To this purpose, centrifugation at 14,000 rpm for $15 \mathrm{~min}$ was performed on freshly cross-linked nanohydrogels suspended in oil. Nanohydrogels were rinsed with deionized water and resuspended in water after $10 \mathrm{~min}$ of ultrasound exposure.

\subsection{Dimensional and Morphological Characterization}

Dynamic light scattering (DLS, Zetasizer Nano ZS90, Malvern Instruments, Malvern, Worcestershire, UK) was employed to evaluate the particle size and colloidal stability over time. The temperature was set at $25^{\circ} \mathrm{C}$, and the scattering angle was $90^{\circ}$. All the measurements were performed in triplicate. Miniemulsions, oily, and aqueous suspensions of nanohydrogels were analyzed. For size analyses, $1 \mathrm{~mL}$ of sample was inserted into a disposable polystyrene cuvette with no preliminary dilution. The size and morphology of the particles were also investigated via Field Emission Scanning Electron Microscopy (FE-SEM Zeiss MERLIN, Carl Zeiss NTS GmbH, Oberkochen, Germany). The aqueous suspension of nanohydrogels was dried at room temperature for a week, and the residue was placed on a SEM stub before undergoing metallization. The SEM accelerating voltage was set at $3 \mathrm{KeV}$, the working distance was $3 \mathrm{~mm}$, and an InLens detector was used.

\subsection{Release Tests}

Dialysis tests were performed to evaluate the release profile of dicamba. A cellulose membrane with a molecular cut-off of 14,000 Da (Sigma-Aldrich, Cesano Maderno, Italy) was employed to allow the permeation of dicamba while retaining the nanocarrier. The membrane was preconditioned by immersion in $0.17(v / v) \% \mathrm{NaOH}$ solution. The concentration of the buffer solution was selected to counterbalance the osmotic pressure due to $\mathrm{NaOH}$ in the nanohydrogels.

Release from non-encapsulated and encapsulated dicamba formulations were compared. For both formulations, the continuous phase was the oily phase. Encapsulated dicamba (i.e., dicamba-loaded nanohydrogels) was prepared following the procedure described in Section 2.2. Non-encapsulated dicamba was prepared following the same procedure but without alginate in the dispersed water phase.

First, $40 \mathrm{~mL}$ of oily nanohydrogel suspension or dicamba-loaded miniemulsion were inserted inside the membrane, which was then sealed with clippers and immersed in $0.75 \mathrm{~L}$ of buffer solution, i.e., $0.17(v / v) \% \mathrm{NaOH}$ solution. The system was gently mixed throughout the whole release test and covered with an aluminum foil because of the dicamba photosensitivity. The release tests were carried out at room temperature $\left(20^{\circ} \mathrm{C}\right)$. Three $\mathrm{mL}$ were periodically withdrawn from the buffer compartment and immediately reintegrated with fresh buffer solution. The samples were analyzed by UV/VIS spectrophotometry (Specord S 600, Analytik Jena AG, Jena, Germany) using the buffer solution as a blank. The absorption peak at $281 \mathrm{~nm}$ was associated with the presence of released dicamba, since neither continuous oily phase nor alginate showed any absorbance at that wavelength. This peak was used to evaluate the pesticide concentration.

\section{Results and Discussion}

\subsection{Design of Miniemulsion Formulation and Operative Conditions}

The miniemulsion template for the synthesis of alginate nanohydrogels is composed of a continuous oily phase and a dispersed aqueous phase. The phase configuration was dictated by the hydrophilicity of dicamba. The selected materials respond to the biodegradability and biocompatibility constraints imposed by the environmental application of the delivery platform. The miniemulsion formulation was first optimized in terms of surfactant concentration and mixing speed. The selection of Pluronic PE 6100 as a proper surfactant for the stabilization of an inverse miniemulsion has been reported in our previous publication [31]. The surfactant concentration was progressively increased from 0.25 to $0.4 \mathrm{~g}$ in $75 \mathrm{~mL}$ of sunflower oil (samples M1-M4 in Table 1), and the miniemulsion was analyzed via DLS. Table 2 reports a non-linear trend of the drops dimension as a function of the amount of surfactant. For Pluronic < $0.35 \mathrm{~g}$ (samples M1 and M2), unimodal dimensional 
distributions were obtained, and the droplet size decreased in agreement with Gibbs law. For surfactant $\geq 0.35 \mathrm{~g}$ (samples M3, M4, and M5), a bimodal dimensional distribution was obtained, as shown in Figure S1 for sample M4, resulting in higher Z-average size. The distinct features of the samples were also highlighted by the polydispersity index (PDI). PDI was around 0.2 for Pluronic $<0.35 \mathrm{~g}$, which denotes a fine control over droplet size exerted by the homogenization step. By contrast, larger surfactant concentrations led to polydisperse values of droplet size, which was probably because of competitive micellization and coalescence phenomena. Thus, $0.3 \mathrm{~g}$ of Pluronic was selected as the optimal amount of surfactant, which guaranteed a monodisperse droplet size around $25 \mathrm{~nm}$.

Table 2. Z-average and PDI evaluated by DLS on miniemulsion droplets prepared with increasing amounts of Pluronic PE 6100 in the continuous phase and increasing homogenization speed.

\begin{tabular}{cccccc}
\hline $\begin{array}{c}\text { Sample } \\
\text { Code }\end{array}$ & Pluronic, $\mathbf{g}$ & $\begin{array}{c}\text { UT Speed, } \\
\text { rpm }\end{array}$ & $\begin{array}{c}\text { Z-Average, } \\
\mathbf{n m}\end{array}$ & Std Dev, nm & PDI, - \\
\hline M1 & 0.25 & 14,000 & 52.2 & 8.0 & 0.19 \\
M2 & 0.30 & 14,000 & 26.7 & 6.2 & 0.23 \\
M3 & 0.35 & 14,000 & 73.6 & 19.8 & 0.46 \\
M4 & 0.40 & 14,000 & 82.7 & 13.6 & 0.58 \\
M5 & 0.30 & 8000 & 131.6 & 77.1 & 0.92 \\
M6 & 0.30 & 10,000 & 21.4 & 3.0 & 0.29 \\
\hline
\end{tabular}

The effect of the homogenization speed on the miniemulsion features was also investigated with DLS. The speed range was $8000-14,000 \mathrm{rpm}$ (see samples M2, M5, and M6). As listed in Table 2, a drop size around $25 \mathrm{~nm}$ and PDI $<0.3$ was obtained only above 10,000 rpm. Further increases in the homogenization speed (sample M3) were not effective in reducing drop size because of the equilibration between breakage and coalescence phenomena. As a drawback, too high speeds could result in excessive heating of the suspension because of the Joule effect and may justify the slightly higher dispersion of dimensional values. Instead, lower speeds led to not reproducible results, implying that the miniemulsion was not properly formed and stabilized. Relative standard deviations around $50 \%$ and PDI close to 1 corroborated the experimental evidence. Therefore, the homogenization speed was set at 10,000 rpm to guarantee a narrow dimensional distribution of miniemulsion droplets, as highlighted in Figure 2 (sample M6).

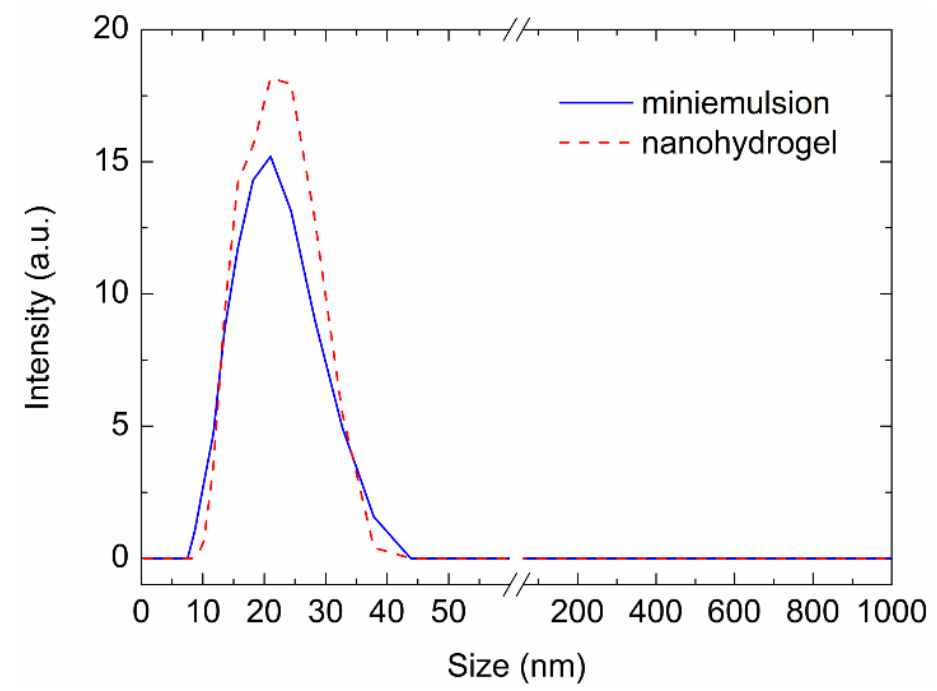

Figure 2. Comparison between miniemulsion droplet (sample M6) and nanohydrogel (sample H2) dimensional distributions obtained by DLS. The templating effect of miniemulsion is highlighted by the overlapping of the two curves. 


\subsection{Nanohydrogel Synthesis}

After the optimization of the miniemulsion formation, the synthesis of nanohydrogels was investigated. Nanohydrogels are identified with the prefix $\mathrm{H}$. To trigger alginate cross-linking, $\mathrm{CaCl}_{2}$ was added to the suspension during the homogenization step. A comparison between the dimensional distribution of miniemulsion droplets (sample M6) and nanohydrogel oily suspension (sample H2) is reported in Figure 2. A good overlapping between the two curves was observed and was attributed to the templating effect of miniemulsion cross-linking. Therefore, the miniemulsion droplet size $(21.4 \pm 3.0 \mathrm{~nm})$ determines the final hydrogel size $(20.6 \pm 4.4 \mathrm{~nm})$. The PDI was 0.29 and 0.14 for the miniemulsion and the nanohydrogel suspension, respectively. All the evidence pointed out that the physical cross-linking process did not lead to aggregation phenomena among the particles nor altered the monodispersity of the system.

A further investigation of the miniemulsion templating effect was carried out by analyzing the size of nanohydrogels prepared at different homogenization speed, which is reported in Table 3 (samples H1-H3).

Table 3. Z-average and PDI evaluated by DLS on nanohydrogels prepared with increasing homogenization speed and with different amounts of sodium alginate.

\begin{tabular}{cccccc}
\hline $\begin{array}{c}\text { Sample } \\
\text { Code }\end{array}$ & $\begin{array}{c}\text { UT Speed, } \\
\text { rpm }\end{array}$ & $\begin{array}{c}\text { Alginate, wt } \\
\mathbf{\%}\end{array}$ & $\begin{array}{c}\text { Z-Average, } \\
\mathbf{n m}\end{array}$ & Std Dev, nm & PDI, - \\
\hline H1 & 8000 & 1 & 112.3 & 90.5 & 0.75 \\
H2 & 10,000 & 1 & 20.6 & 4.4 & 0.14 \\
H3 & 14,000 & 1 & 19.3 & 0.3 & 0.35 \\
H4 & 10,000 & 2 & 35.2 & 13.5 & 0.36 \\
\hline
\end{tabular}

The same UT speeds of the study on miniemulsions were considered. The results concerning the average size and PDI were in good agreement with those obtained for the corresponding miniemulsion droplets reported in Table 2. At $8000 \mathrm{rpm}(\mathrm{H} 1)$, the unstable miniemulsion led to bimodal distributions of hydrogels, pointing out peaks around 50 and $125 \mathrm{~nm}$, as reported in Figure S2. Instead, higher speeds resulted in populations of nanoparticles with reproducible and finely tuned size. Speeds as high as 14,000 rpm led to slightly more dispersed populations, which was probably because of the consequence of excessive heating. Thanks to the preservation of size, the dimensional features of the nanohydrogels could easily be tuned by acting on the miniemulsion formation process.

The stability of miniemulsion droplets and nanohydrogel suspensions was also tested over time. Samples were prepared by setting 10,000 rpm as the homogenization speed. Reference samples are M6 and H2. As can be seen in Figure 3, the dimensional and PDI trends pointed out the beneficial effect of alginate cross-linking over particle stability. A progressive increase in the drop size was observed for the miniemulsion as a consequence of constructive collision phenomena due to Ostwald ripening. The droplet size doubled in just two days, denoting a strong instability of the system. Conversely, the nanohydrogel suspension did not show any appreciable dimensional or PDI variation over the testing time. Thus, miniemulsions had to be freshly prepared and immediately cross-linked to preserve the particle size and benefit from the dimensional template. Nevertheless, the nanohydrogel suspension was stable and could be employed for release studies. 


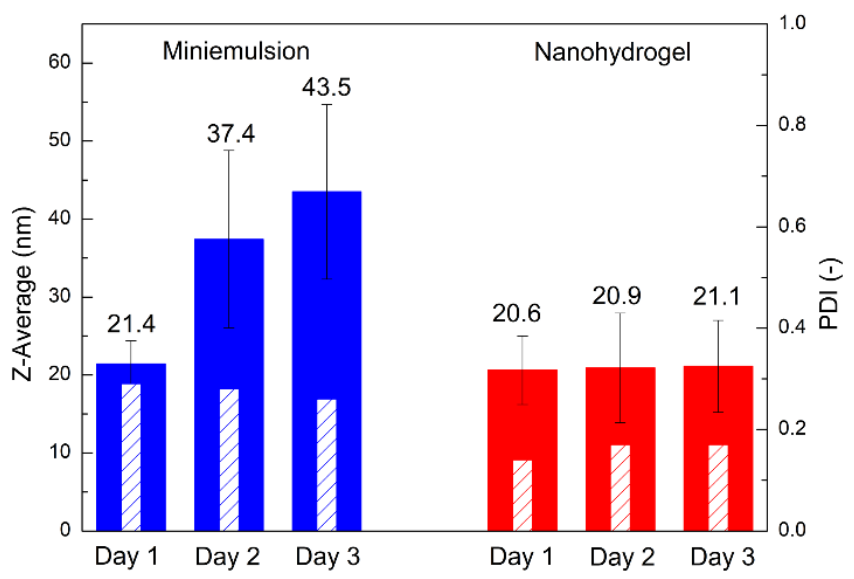

Figure 3. Comparison between miniemulsion (sample M6) and nanohydrogel (sample H2) size (left-hand y axis) and PDI stability (right-hand y-axis) over time.

Lastly, the impact of alginate concentration on the features of the particles was investigated. Doubling alginate concentration $(2 \mathrm{wt} \%$, sample $\mathrm{H} 4)$ led to larger and more dispersed nanoparticles populations, as reported in Table 3 . The effect was attributed to the increased viscosity of alginate solutions and inter-particle cross-linking. Therefore, $1 \mathrm{wt} \%$ alginate was selected as the optimal hydrogel precursor for the following study on particle loading and release.

\subsection{Loading of the Nanohydrogels with Dicamba}

Nanohydrogels prepared according to the optimized set of synthesis conditions (H2) were loaded with dicamba. Final concentrations of dicamba ranging from 1 to $125 \mathrm{mg} / \mathrm{mL}$ in the $0.2 \mathrm{M} \mathrm{CaCl}_{2}$ phase were tested to evaluate their impact on the nanoparticle distributions (samples HD1-HD4 in Table 4). As a general trend, dicamba did not significantly disturb the nanohydrogel formation nor did it perturb the particle size distribution and colloidal stability, even at high loadings. Table 4 lists the average size and PDI of the loaded nanohydrogels.

Table 4. Z-average and PDI evaluated by DLS on dicamba-loaded nanohydrogels, prepared with H2 procedure with increasing dicamba concentrations.

\begin{tabular}{ccccc}
\hline Sample Code & $\begin{array}{c}\text { Dicamba, } \\
\mathbf{m g} / \mathbf{m L}\end{array}$ & Z-Average, $\mathbf{n m}$ & Std Dev, $\mathbf{n m}$ & PDI, - \\
\hline HD1 & 1 & 15.0 & 1.9 & 0.03 \\
HD2 & 3 & 21.3 & 3.2 & 0.07 \\
HD3 & $30(+\mathrm{NaOH})$ & 23.3 & 0.23 & 0.23 \\
HD4 & $125(+\mathrm{NaOH})$ & 27.8 & 4.6 & 0.17 \\
\hline
\end{tabular}

The direct incorporation method for dicamba loading guaranteed the preservation of the templating effect of miniemulsion and did not alter the quality attributes of the nanocarrier. Such a method could potentially be applied to any hydrophilic substance to be encapsulated. The different hydrophilicity of the continuous and the dispersed phases of the miniemulsion determined the preferential location of the active principle within the drops. A confinement effect was exerted by the surrounding hydrophobic environment, ensuring negligible migration of the encapsulated substance out of the carrier.

It is worth mentioning that the final nanohydrogel particle size and its substantial stability over time make this nanoformulation largely compatible with its field-scale application using conventional herbicide spray equipment, in which eventual nanoparticle aggregation can lead to nozzle clogging and therefore deviation from the desired spray pattern. In fact, in these systems, the average drop size applied to the targeted leaves, 
controlled by the combination of nozzle size and applied pressure, can range from less than 60 to more than $650 \mu \mathrm{m}$ [53-55].

\subsection{Controlled Release of Dicamba}

The release ability of the nanocarriers was tested by means of dialysis tests. Release tests were performed on non-encapsulated and encapsulated dicamba formulations, which were both dispersed in the sunflower oil used for the synthesis. This choice was in view of the potential use of the dicamba-alginate nanohydrogels for the development of an emulsifiable concentrate (EC), that is, an oil-based pesticide formulation which, thanks to the addition of surfactants and other co-formulants when developing the commercial product, can be diluted in water by the farmer prior to application. Despite the less common use of such a type of pesticide formulation compared to water-based products, this route was preferred to preserve the alginate nanohydrogels from premature degradation and/or dicamba release [56,57]. The use of a food-grade oil overcomes most of the environmental and health criticalities associated to ECs, which were traditionally based on mineral oils [58,59]. Moreover, oils are quite commonly used as adjuvants and wetting agents in dicamba-based pesticides to improve the leaf uptake of the compound.

Preliminary release tests were carried out on unloaded nanohydrogels and confirmed the complete retention of alginate nanoparticles by the dialysis membrane and the absence of free alginate. Then, the performances of freshly prepared non-encapsulated and encapsulated formulations of dicamba were compared. For these tests, both the miniemulsion and the nanohydrogels were prepared using a dicamba concentration of $100 \mathrm{mg} / \mathrm{mL}$ in water and in $0.2 \mathrm{M} \mathrm{CaCl}_{2}$. As reported in our previous study [31], water-soluble compounds can be successfully confined in the aqueous dispersed phase, i.e., inside the nanohydrogels, of inverse miniemulsions, achieving unitary encapsulation efficiency of AIs.

Cumulative release curves are reported in Figure 4. The cumulative released mass $m_{c}(t)$ was obtained as:

$$
m_{c}(t)=V_{\mathrm{b}} C(t)+V \sum_{i=0}^{t-1} C_{i}
$$

where $V_{\mathrm{b}}$ is the buffer volume, $C$ is the dicamba concentration, $V$ is the withdrawal volume, and $t$ is the time. The percentage of released dicamba was expressed as the ratio between the cumulative released mass over the dicamba loading.

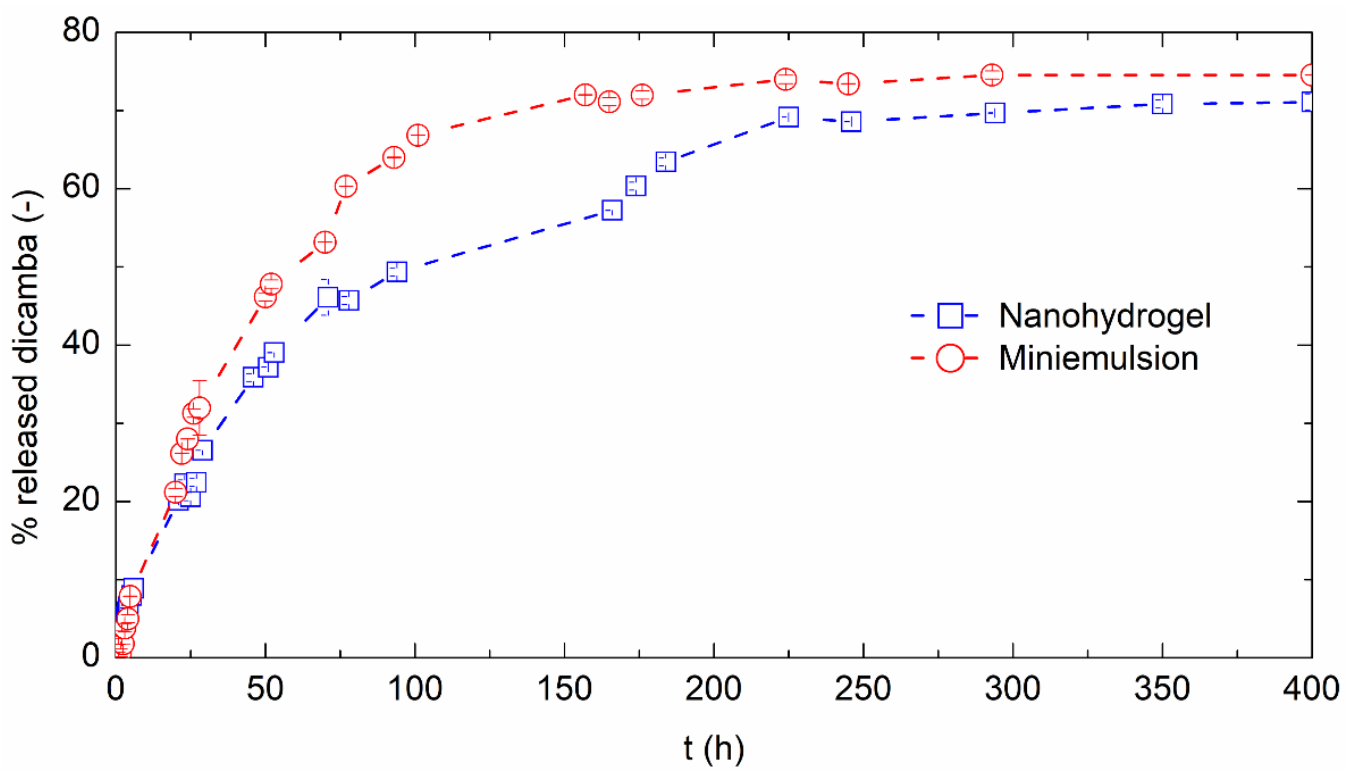

Figure 4. Cumulative percentage of non-encapsulated and encapsulated released dicamba. The percentage was calculated taking the dicamba mass loaded in the miniemulsion/nanohydrogels as a reference. 
Firstly, the non-encapsulated dicamba formulation was studied. Thus, a dicambaloaded miniemulsion was prepared, and the release of dicamba was monitored over time. The synthesis conditions were those of sample M6, but the dispersed phase of the miniemulsion did not comprehend alginate. Most (73.1\%) of the loaded dicamba was released within $120 \mathrm{~h}$. For the encapsulated formulation, a sustained dicamba release was observed for the first $75 \mathrm{~h}$, which was followed by a slower release phase. Equilibrium was reached after $250 \mathrm{~h}$, and the total released dicamba was equal to $71.1 \%$ of the loading. Several reasons could justify the incomplete release observed for both encapsulated and non-encapsulated oily formulations, including the interaction between dicamba and $\mathrm{NaOH}$ as well as the depletion of the driving force due to the dicamba gradient in chemical potential between the acceptor and receptor compartments.

As expected, the encapsulation of dicamba did not affect the total released quantity, confirming the absence of significative interactions between the cross-linking protocol of nanohydrogels and the presence of dicamba. The encapsulated dicamba formulation promoted a prolonged and more controlled release of the pesticide compared to the miniemulsion. In addition, the polymeric matrix embedding the active substance can serve as a protector from external stresses and can safeguard the pesticide from soil washing-out.

To provide insight in the mechanism of release, the experimental data were leastsquares fitted to different kinetic models. Table 5 reports the tested models, the relative equation, and the determination coefficient. $F$ is the released fraction of dicamba, and $k_{i}$ represents the various kinetic constants. The values of all fitted parameters are reported in the SI (Table S1).

Table 5. Fitting of the experimental release data with different kinetic models. The model equation and the dispersive coefficient are reported.

\begin{tabular}{ccc}
\hline Kinetic Release Model & Model Equation & $\mathbf{R}^{\mathbf{2}}$ \\
\hline Zero Order & $F=k_{\mathrm{o}} t$ & 0.78 \\
First Order & $\ln (1-F)=-k_{1} t$ & 0.90 \\
Higuchi & $F=k_{\mathrm{H}} t^{1 / 2}$ & 0.98 \\
Hixson-Crowell & $1-(1-F)^{1 / 3}=k_{\mathrm{HC}} t$ & 0.87 \\
Baker-Lonsdale & $3 / 2\left[1-(1-F)^{2 / 3}\right]-F=k_{\mathrm{BL}} t$ & 0.99 \\
\hline
\end{tabular}

The Higuchi $\left(R^{2}=0.98\right)$ and the Baker-Lonsdale $\left(R^{2}=0.99\right)$ models best describe the experimental release trends, pointing out a diffusion-dominated release. More specifically, the Baker-Lonsdale model is derived from the Higuchi model, which accounts for the release from semi-solid or solid matrixes, considering the release carrier as a sphere. It was hypothesized that the nanohydrogels were attracted by the hydrophilic dialysis membrane, favoring their accumulation at the solid-liquid interface and thus facilitating the diffusive release of the pesticide through the interstitial water [31]. In this way, the release of a hydrophilic compound from an oily formulation was studied.

The timing here observed for the release of dicamba from the nanohydrogel is compatible with the needs of a field-scale application of the nanopesticide. An effective nanoformulation of dicamba is expected to release the $\mathrm{AI}$ in a few tens of hours, thus preventing its volatilization (which mainly occurs during spraying itself and in a short time after application) without hindering plant uptake itself. The alginate nanoparticles synthesized in this study released less than $30 \%$ of the loaded AI in $24 \mathrm{~h}$. When sprayed on target weeds, dicamba is translocated in all the parts of the weed in a few hours, with a predominant uptake in leaves: it was observed [60] that more than $40 \%$ of the AI applied on sensible weeds was absorbed by leaves and only about $5 \%$ was detected in roots. Noticeably, the encapsulation of dicamba in the nanohydrogel is not expected to hinder uptake: the intake of hydrophilic nanoparticles is mediated by the presence of an aqueous phase connecting the external part of the leaf with the internal one. The thickness of this medium, typically in the order of $50 \mathrm{~nm}$, determines the upper threshold value of nanoparticles size that can 
easily enter stomata [61]. As a consequence, nanoparticles with an average size lower than $42 \mathrm{~nm}$ could easily enter plant stomata, increasing herbicides' efficacy [62].

Lastly, nanohydrogels were separated from the oily synthesis medium and redispersed in a hydrophilic medium in order to mimic the pesticide dilution for field application. After reconstitution, the nanohydrogel aqueous suspension did not show appreciable variations in size $(21.3 \pm 6.7 \mathrm{~nm})$ or PDI (0.19) compared to the oily suspension. Nonetheless, nanohydrogels showed a slight tendency to swelling over time, unlike the oil-based formulation. A $40 \%$ increase in particle size was registered after two days from reconstitution. Then, both size $(29.8 \pm 0.24 \mathrm{~nm})$ and PDI (0.22) stabilized over time. The spherical shape of the particles, their monodispersity, and their size in the range of a few tens of nanometers were confirmed by SEM investigation, as shown by the micrographs in Figure 5.
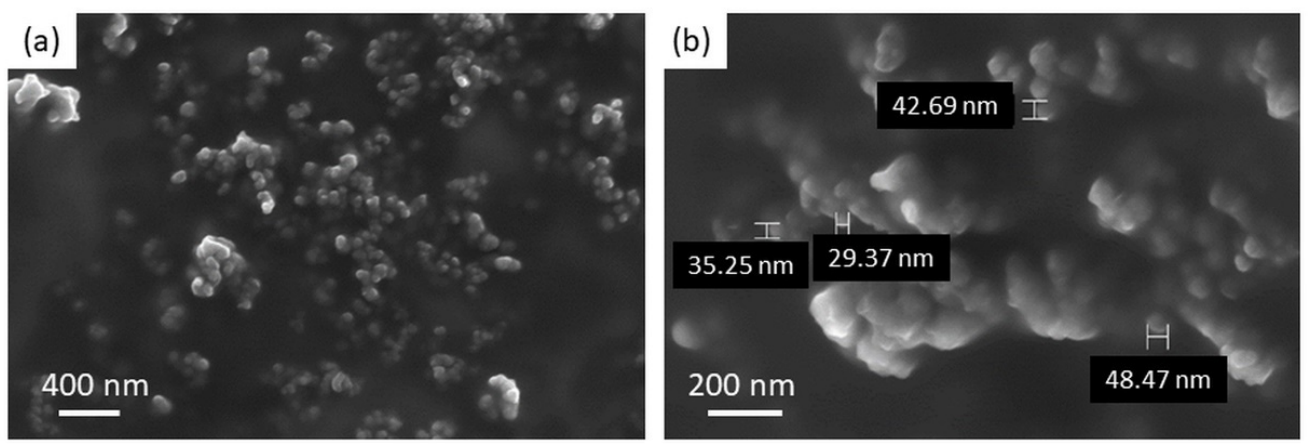

Figure 5. (a,b) SEM micrographs of alginate nanoparticles.

\section{Conclusions}

The synthesis of biocompatible nanohydrogels suitable for the encapsulation of hydrophilic substances and their application to the controlled release of a model pesticide were here discussed. The preparation of miniemulsion templates was optimized, and the cross-linked formulation was proved to be stable over time. Alginate nanohydrogels promoted the controlled and sustained release of dicamba over more than two weeks, thus representing an ideal platform for environmental applications. The nanoformulation of the pesticide slowed down the release rate and exerted a protective action toward hydrophilic active substances.

Even though specific uptake studies were not carried out in this work, these results suggest that the nanoformulation herein synthesized can effectively prevent volatilization without hindering dicamba uptake by target weeds, thanks to the combination of the AI slow release and the reduced particle size, which is small enough to enter leaf stomata.

Alginate nanohydrogels synthesized starting from an emulsified template were proved to effectively encapsulate dicamba and control its prolonged and sustained release over time. The proposed biocompatible formulation has the potential to be applied to a large spectrum of hydrophilic compounds and expand their applicability in the environmental field.

Supplementary Materials: The following are available online at https:/ /www.mdpi.com/article/10 .3390/pr9091641/s1, Figure S1: Size distribution of miniemulsion droplets of sample M4 obtained by DLS; Figure S2: Size distribution of the nanohydrogel of sample H1 obtained by DLS; Table S1: Fitted parameters of kinetic models of dicamba release from encapsulated and non-encapsulated formulations of dicamba.

Author Contributions: Conceptualization, F.A., R.P. and T.T.; methodology, F.A., R.P. and T.T.; formal analysis, F.A., D.C., M.G.; investigation, D.C.; writing—original draft preparation, F.A. and M.G.; writing - review and editing, R.P. and T.T.; supervision, R.P. and T.T.; funding acquisition, T.T. All authors have read and agreed to the published version of the manuscript.

Funding: This research was funded by the project Nanograss co-funded by Compagnia di San Paolo. 
Institutional Review Board Statement: Not applicable.

Informed Consent Statement: Not applicable.

Acknowledgments: G.G. is kindly acknowledged for supporting the experimental activity. The authors also wish to thank S.C. for the support in the manuscript proofreading.

Conflicts of Interest: The authors declare no conflict of interest. The funders had no role in the design of the study; in the collection, analyses, or interpretation of data; in the writing of the manuscript, or in the decision to publish the results.

\section{References}

1. Alavanja, M.C.R. Introduction: Pesticides use and exposure extensive worldwide. Rev. Environ. Health 2009, 24, 303-309. [CrossRef] [PubMed]

2. Kah, M.; Kookana, R. Emerging investigator series: Nanotechnology to develop novel agrochemicals: Critical issues to consider in the global agricultural context. Environ. Sci. Nano 2020, 7, 1867-1873. [CrossRef]

3. United Nations, Department of Economic and Social Affairs, Population Division. World Population Prospects. 2019. Available online: https: / population.un.org/wpp/Publications / (accessed on 28 July 2021).

4. Popp, J.; Pető, K.; Nagy, J. Pesticide productivity and food security. A review. Agron. Sustain. Dev. 2013, 33, 243-255. [CrossRef]

5. Oerke, E.C. Crop losses to pests. J. Agric. Sci. 2006, 144, 31-43. [CrossRef]

6. Pimentel, D.; Burgess, M. Small amounts of pesticides reaching target insects. Environ. Dev. Sustain. 2012, 14, 1-2. [CrossRef]

7. Aktar, M.W.; Sengupta, D.; Chowdhury, A. Impact of pesticides use in agriculture: Their benefits and hazards. Interdiscip. Toxicol. 2009, 2, 1-12. [CrossRef]

8. Fenner, K.; Canonica, S.; Wackett, L.P.; Elsner, M. Evaluating Pesticide Degradation in the Environment: Blind Spots and Emerging Opportunities. Science 2013, 341, 752-758. [CrossRef]

9. Silva, V.; Mol, H.G.J.; Zomer, P.; Tienstra, M.; Ritsema, C.J.; Geissen, V. Pesticide residues in European agricultural soils-A hidden reality unfolded. Sci. Total Environ. 2019, 653, 1532-1545. [CrossRef] [PubMed]

10. Krieger, R.I. Preface. In Handbook of Pesticide Toxicology, 2nd ed.; Krieger, R.I., Krieger, W.C., Eds.; Academic Press: San Diego, CA, USA, 2001; pp. xxv-xxvi.

11. Kah, M.; Brown, C.D. Prediction of the adsorption of ionizable pesticides in soils. J. Agric. Food Chem. 2007, 55, 2312-2322. [CrossRef] [PubMed]

12. Villaverde, J.; Kah, M.; Brown, C.D. Adsorption and degradation of four acidic herbicides in soils from southern Spain. Pest Manag. Sci. 2008, 64, 703-710. [CrossRef] [PubMed]

13. Sakaliene, O.; Papiernik, S.K.; Koskinen, W.C.; Spokas, K.A. Sorption and predicted mobility of herbicides in Baltic soils. J. Environ. Sci. Health B 2007, 42, 641-647. [CrossRef]

14. Roy, J.W.; Hall, J.C.; Parkin, G.W.; Wagner-Riddle, C.; Clegg, B.S. Seasonal leaching and biodegradation of dicamba in turfgrass. J. Environ. Qual. 2001, 30, 1360-1370. [CrossRef]

15. Spadotto, C.A.; Hornsby, A.G.; Gomes, M.A. Sorption and leaching potential of acidic herbicides in Brazilian soils. J. Environ. Sci. Health B 2005, 40, 29-37. [CrossRef]

16. Tindall, J.A.; Vencill, W.K. Transport of Atrazine, 2,4-D, and Dicamba through Preferential Flowpaths in an Unsaturated Claypan Soil near Centralia, Missouri. J. Hydrol. 1995, 166, 37-59. [CrossRef]

17. Riter, L.S.; Sall, E.D.; Pai, N.; Beachum, C.E.; Orr, T.B. Quantifying Dicamba Volatility under Field Conditions: Part I, Methodology. J. Agric. Food Chem. 2020, 68, 2277-2285. [CrossRef]

18. Bish, M.D.; Farrell, S.T.; Lerch, R.N.; Bradley, K.W. Dicamba Losses to Air after Applications to Soybean under Stable and Nonstable Atmospheric Conditions. J. Environ. Qual. 2019, 48, 1675-1682. [CrossRef]

19. Gavlick, W.; Wright, D.; MacInnes, A.; Hemminghaus, J.; Webb, J.; Yermolenka, V.; Su, W. A Method to Determine the Relative Volatility of Auxin Herbicide Formulations. In Pesticide Formulation and Delivery Systems: 35th Volume, Pesticide Formulations, Adjuvants, and Spray Characterization in 2014; Goss, G., Ed.; ASTM International: West Conshohocken, PA, USA, 2016; pp. 24-32.

20. Sciumbato, A.S.; Chandler, J.M.; Senseman, S.A.; Bovey, R.W.; Smith, K.L. Determining exposure to auxin-like herbicides. II. Practical application to quantify volatility. Weed Technol. 2004, 18, 1135-1142. [CrossRef]

21. Mueller, T.C. Methods To Measure Herbicide Volatility. Weed Sci. 2015, 63, 116-120. [CrossRef]

22. Moulick, R.G.; Das, S.; Debnath, N.; Bandyopadhyay, K. Potential use of nanotechnology in sustainable and 'smart' agriculture: Advancements made in the last decade. Plant Biotechnol. Rep. 2020, 14, 505-513. [CrossRef]

23. Kumar, S.; Nehra, M.; Dilbaghi, N.; Marrazza, G.; Hassan, A.A.; Kim, K.H. Nano-based smart pesticide formulations: Emerging opportunities for agriculture. J. Control. Release 2019, 294, 131-153. [CrossRef]

24. Vurro, M.; Miguel-Rojas, C.; Perez-de-Luque, A. Safe nanotechnologies for increasing the effectiveness of environmentally friendly natural agrochemicals. Pest Manag. Sci. 2019, 75, 2403-2412. [CrossRef]

25. Guha, T.; Gopal, G.; Kundu, R.; Mukherjee, A. Nanocomposites for Delivering Agrochemicals: A Comprehensive Review. J. Agric. Food Chem. 2020, 68, 3691-3702. [CrossRef] 
26. Shakiba, S.; Astete, C.E.; Paudel, S.; Sabliov, C.M.; Rodrigues, D.F.; Louie, S.M. Emerging investigator series: Polymeric nanocarriers for agricultural applications: Synthesis, characterization, and environmental and biological interactions. Environ. Sci. Nano 2020, 7, 37-67. [CrossRef]

27. Strachan, S.D.; Casini, M.S.; Heldreth, K.M.; Scocas, J.A.; Nissen, S.J.; Bukun, B.; Lindenmayer, R.B.; Shaner, D.L.; Westra, P.; Brunk, G. Vapor Movement of Synthetic Auxin Herbicides: Aminocyclopyrachlor, Aminocyclopyrachlor-Methyl Ester, Dicamba, and Aminopyralid. Weed Sci. 2010, 58, 103-108. [CrossRef]

28. Marei, A.S.; Soltan, H.R.; Mousa, A.; Khamis, A. Leaching and mobility of carbofuran from granular and alginate controlled release formulations. J. Agric. Sci. 2000, 134, 405-412. [CrossRef]

29. Johnson, R.M.; Pepperman, A.B. Soil Column Mobility of Metribuzin from Alginate-Encapsulated Controlled Release Formulations. J. Agric. Food Chem. 1995, 43, 241-246. [CrossRef]

30. Song, B.; Liang, H.; Sun, R.; Peng, P.; Jiang, Y.; She, D. Hydrogel synthesis based on lignin/sodium alginate and application in agriculture. Int. J. Biol. Macromol. 2020, 144, 219-230. [CrossRef] [PubMed]

31. Artusio, F.; Ferri, A.; Gigante, V.; Massella, D.; Mazzarino, I.; Sangermano, M.; Barresi, A.; Pisano, R. Synthesis of high payload nanohydrogels for the ecapsulation of hydrophilic molecules via inverse miniemulsion polymerization: Caffeine as a case study. Drug Dev. Ind. Pharm. 2019, 45, 1862-1870. [CrossRef]

32. Azmi, N.A.N.; Elgharbawy, A.A.M.; Motlagh, S.R.; Samsudin, N.; Salleh, H.M. Nanoemulsions: Factory for Food, Pharmaceutical and Cosmetics. Processes 2019, 7, 617. [CrossRef]

33. Innocente, N.; Biasutti, M.; Venir, E.; Spaziani, M.; Marchesini, G. Effect of high-pressure homogenization on droplet size distribution and rheological properties of ice cream mixes. J. Dairy Sci. 2009, 92, 1864-1875. [CrossRef]

34. Shahavi, M.H.; Hosseini, M.; Jahanshahi, M.; Meyer, R.L.; Darzi, G.N. Evaluation of critical parameters for preparation of stable clove oil nanoemulsion. Arab. J. Chem. 2019, 12, 3225-3230. [CrossRef]

35. Solans, C.; Izquierdo, P.; Nolla, J.; Azemar, N.; Garcia-Celma, M.J. Nano-emulsions. Curr. Opin. Colloid Interface Sci. 2005, 10, 102-110. [CrossRef]

36. Mason, T.G.; Wilking, J.N.; Meleson, K.; Chang, C.B.; Graves, S.M. Nanoemulsions: Formation, structure, and physical properties. J. Phys. Condens. Matter 2006, 18, R635-R666. [CrossRef]

37. Cao, Z.H.; Ziener, U. Synthesis of nanostructured materials in inverse miniemulsions and their applications. Nanoscale 2013, 5, 10093-10107. [CrossRef] [PubMed]

38. Landfester, K.; Willert, M.; Antonietti, M. Preparation of polymer particles in nonaqueous direct and inverse miniemulsions. Macromolecules 2000, 33, 2370-2376. [CrossRef]

39. Capek, I. On inverse miniemulsion polymerization of conventional water-soluble monomers. Adv. Colloid Interface Sci. 2010, 156, 35-61. [CrossRef]

40. Anton, N.; Benoit, J.P.; Saulnier, P. Design and production of nanoparticles formulated from nano-emulsion templates-a review. J. Control. Release 2008, 128, 185-199. [CrossRef] [PubMed]

41. Artusio, F.; Bazzano, M.; Pisano, R.; Coulon, P.-E.; Rizza, G.; Schiller, T.; Sangermano, M. Polymeric nanocapsules via interfacial cationic photopolymerization in miniemulsion. Polymer 2018, 139, 155-162. [CrossRef]

42. Schork, F.J.; Luo, Y.; Smulders, W.; Russum, J.P.; Butté, A.; Fontenot, K. Miniemulsion Polymerization. In Polymer Particles; Okubo, M., Ed.; Springer: Berlin/Heidelberg, Germany, 2005; pp. 129-255.

43. Mora-Huertas, C.E.; Fessi, H.; Elaissari, A. Polymer-based nanocapsules for drug delivery. Int. J. Pharm. 2010, 385 , 113-142. [CrossRef]

44. Faucheu, J.; Gauthier, C.; Chazeau, L.; Cavaillé, J.-Y.; Mellon, V.; Lami, E.B. Miniemulsion polymerization for synthesis of structured clay/polymer nanocomposites: Short review and recent advances. Polymer 2010, 51, 6-17. [CrossRef]

45. Weiss, C.K.; Landfester, K. Miniemulsion Polymerization as a Means to Encapsulate Organic and Inorganic Materials. In Hybrid Latex Particles: Preparation with (Mini)emulsion Polymerization; van Herk, A.M., Landfester, K., Eds.; Springer: Berlin/Heidelberg, Germany, 2010; pp. 185-236.

46. Asua, J.M. Miniemulsion polymerization. Prog. Polym. Sci. 2002, 27, 1283-1346. [CrossRef]

47. Paques, J.P.; van der Linden, E.; van Rijn, C.J.; Sagis, L.M. Preparation methods of alginate nanoparticles. Adv. Colloid Interface Sci. 2014, 209, 163-171. [CrossRef] [PubMed]

48. Nörnberg, A.B.; Gehrke, V.R.; Mota, H.P.; Camargo, E.R.; Fajardo, A.R. Alginate-cellulose biopolymeric beads as efficient vehicles for encapsulation and slow-release of herbicide. Colloids Surf. Physicochem. Eng. Aspects 2019, 583, 123970. [CrossRef]

49. Sarika, P.R.; James, N.R.; Anil, P.R.; Raj, D.K. Preparation, characterization and biological evaluation of curcumin loaded alginate aldehyde-gelatin nanogels. Mater. Sci. Eng. C 2016, 68, 251-257. [CrossRef]

50. Artusio, F.; Castellví, A.; Sacristán, A.; Pisano, R.; Gavira, J.A. Agarose Gel as a Medium for Growing and Tailoring Protein Crystals. Cryst. Growth Des. 2020, 20, 5564-5571. [CrossRef]

51. Artusio, F.; Castellví, A.; Pisano, R.; Gavira, J.A. Tuning Transport Phenomena in Agarose Gels for the Control of Protein Nucleation Density and Crystal Form. Crystals 2021, 11, 466. [CrossRef]

52. Dalmoro, A.; Barba, A.A.; Lamberti, G.; Grassi, M.; d'Amore, M. Pharmaceutical applications of biocompatible polymer blends containing sodium alginate. Adv. Polym. Tech. 2012, 31, 219-230. [CrossRef]

53. Nuyttens, D.; Baetens, K.; De Schampheleire, M.; Sonck, B. Effect of nozzle type, size and pressure on spray droplet characteristics. Biosys. Eng. 2007, 97, 333-345. [CrossRef] 
54. Antuniassi, U.; Mota, A.; Chechetto, R.; Carvalho, F.; Ovejero, R.; Barbosa, H.; Morris, M.; Araujo, V. Droplet Spectrum Generated by Air Induction Nozzles Spraying Solutions Containing Adjuvants and a Tank Mixture of Glyphosate and Dicamba. In Pesticide Formulation and Delivery Systems: 40th Volume, Formulation, Application and Adjuvant Innovation; Elsik, C., Ed.; ASTM International: West Conshohocken, PA, USA, 2020; p. 36.

55. Putorti, A. Simultaneous Measurements of Drop Size and Velocity in Large-Scale Sprinkler Flows Using Particle Tracking and LaserInduced Fluorescence; National Institute of Standards and Technology: Gaithersburg, MD, USA, 2004. Available online: https: / / tsapps.nist.gov / publication/get_pdf.cfm?pub_id=101399 (accessed on 28 July 2021).

56. Maldonado-Reina, A.J.; López-Ruiz, R.; Garrido Frenich, A.; Arrebola, F.J.; Romero-González, R. Co-formulants in plant protection products: An analytical approach to their determination by gas chromatography-high resolution mass accuracy spectrometry. Talanta 2021, 234, 122641. [CrossRef]

57. ElShafei, G.M.S.; El-Said, M.M.; Attia, H.A.E.; Mohammed, T.G.M. Environmentally friendly pesticides: Essential oil-based w/o/w multiple emulsions for anti-fungal formulations. Ind. Crop. Prod. 2010, 31, 99-106. [CrossRef]

58. Brito, E.S.; de Paula, A.R.; Vieira, L.P.; Dolinski, C.; Samuels, R.I. Combining vegetable oil and sub-lethal concentrations of Imidacloprid with Beauveria bassiana and Metarhizium anisopliae against adult guava weevil Conotrachelus psidii (Coleoptera: Curculionidae). Biocontrol Sci. Technol. 2008, 18, 665-673. [CrossRef]

59. Knowles, A. Recent developments of safer formulations of agrochemicals. Environmentalist 2008, 28, 35-44. [CrossRef]

60. Ghanizadeh, H.; Harrington, K.C.; James, T.K. A comparison of dicamba absorption, translocation and metabolism in Chenopodium album populations resistant and susceptible to dicamba. Crop Protect. 2018, 110, 112-116. [CrossRef]

61. Eichert, T.; Kurtz, A.; Steiner, U.; Goldbach, H.E. Size exclusion limits and lateral heterogeneity of the stomatal foliar uptake pathway for aqueous solutes and water-suspended nanoparticles. Physiol. Plant. 2008, 134, 151-160. [CrossRef] [PubMed]

62. Yadav, A.; Yadav, K. Nanoparticle-Based Plant Disease Management: Tools for Sustainable Agriculture. In Nanobiotechnology Applications in Plant Protection; Abd-Elsalam, K.A., Prasad, R., Eds.; Springer International Publishing: Cham, Switzerland, 2018; pp. 29-61. 